\title{
Behaviour of Self Compacting Concrete Columns with Recycled Brick Aggregates
}

\author{
Sivamalar.C, Nalanth.N, Dhanalakshmi.K
}

\begin{abstract}
Recycled brick aggregates are preferable alternatives to natural aggregates for minimizing exploitation of natural resources. In this investigation, experimental and analytical works are performed to investigate the behaviour of SCC columns constructed using partial replacement of natural aggregates by $R B A$ and reinforced with steel fibres. The parameters considered for this study is proportion of RBA in SCC mixture and the amount of fibres used. The results of this study reveal that the use of $R B A$ in the place of natural aggregates slightly reduces the strength properties, but this reduction compensated by adding mineral admixtures and steel fibres. The analytical results agreed with the experimental results for SCC columns behaviour.
\end{abstract}

Keywords: Recycled Brick Aggregates, Self-Compacting Concrete, mineral admixtures, strength properties

\section{INTRODUCTION}

Self-compacting concrete technology was introduced in Japan and initially used to construct the slabs and beams [1]. SCC mix distributed over the surface by its own weight without any external vibration. So, this type of concrete utilized in applications which need of self-compaction [2]. Brickbats are the lightweight aggregates which are used to preparing concrete specimens in recent years. Demolishing buildings are the major sources of brickbat production [3]. The basic way of disposal of these brickbats is landfill this causes soil pollution [4]. Utilization of brickbats as a partial replacement of natural coarse aggregates in SCC is a new idea to avoid exploitation of natural resources. This experimental study was carried out to investigate the performance of brickbats in the place of natural aggregates in SCC and suggests the feasibility of using brickbats as coarse aggregates. Many of the studies were conducted to investigate the feasibility of the brickbats in SCC. Debeib and Kenai 2008 focused on the investigation in which the fine aggregate replacement were adopted and the results of this investigation exhibited that the mechanical properties of SCC significantly lower than the normal concrete [5]. Elastic modulus of the concrete specimens partially replaced by the brickbat aggregates reduced by $30-40 \%$ of the normal concrete elastic modulus value [6]. Brick bats as a fine aggregate in concrete specimens reduces the water absorption and chloride ion penetration this is due to the result of pozzolanic activity of brick aggregates [7]. Replacement level of coarse aggregate by RBA at $50 \%$ increased the chloride ion penetration and carbonation of the

Revised Manuscript Received on July 18, 2019.

Sivamalar.C, Noorul Islam Centre for Higher Education, Kumaracoil, INDIA

Nalanth.N, Noorul Islam Centre for Higher Education, Kumaracoil, INDIA INDIA concrete compared to the normal concrete. This paper aims to study the feasibility of RBA in SCC by replacing the natural aggregates by RBA at the replacement levels of $30 \%, 40 \%$ and $50 \%$.

\section{SCOPE OF THE INVESTIGATION}

Self-Compacting Concrete due to its superior fresh and hardened state properties has found wide application in the construction industry. Various combination of SCC by utilizing alternative materials in partial replacement or complete replacement to binder, FA and CA have been investigated in many of the works carried out by researcher around the globe [9]. Mix proportion optimization is considered as one of the important parameter in the successful production of SCC with desired flow ability, passing ability and segregation resistance. Most of the works have been carried out based on the guide lines EFNARC 2002, 2005. Reasonable research has been carried out by making use of Construction and demolition waste in the modification of SCC mixes. However, the utilization of RBA which forms a considerable proportion of the construction and demolition waste in the production of SCC has not been given much attention. Also, the application of the same in structural elements requires more focus.

\section{MATERIALS AND METHODS}

From the knowledge attained from the literature study it was decided to utilize fly ash as a supplementary cementitious material as a partial replacement to cement. Also, RBA of size ranging from $10-12 \mathrm{~mm}$ was used in this investigation. The research comprised of determining the properties of the materials used in the production of SCC. The properties of cement which is the primary binding material was determined by using the guidelines given in IS: 456; 10262. The properties of FA and CA were determined by following the guidelines given in IS 2386-3 (1963). The fresh state properties of SCC were evaluated in accordance with the guidelines given in EFNARC and the test on hardened properties. Super plasticizer was used as a water reducing admixture to enhance the workability properties of SCC.

\section{EXPERIMENTAL PROPGRAM}

At the first stage the preliminary test data obtained from the determination of the material properties was adopted in the mix design for M30 grade concrete in accordance with

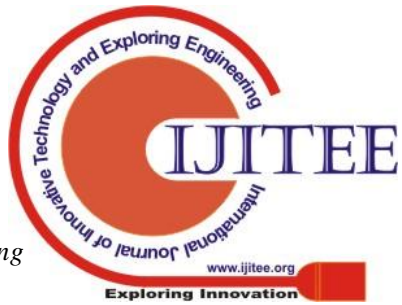


IS and the mix proportion for the control mix was obtained. By following the guidelines given in EFNARC with respect to the mix proportioning of SCC the control mix proportion was adjusted in such a way that the fresh state test like Lbox, slump flow and J-ring tests yielded the limiting values as given in EFNARC. The mixes were so adjusted until an ideal mix proportions satisfying the criteria for SCC was attained. After attaining the ideal mix proportions specimens required for the determination of strength properties of SCC were cast and cured and designated as M0, M1, M2, M3, M4, M5, M6. M0 represents the control mix.M1, M2, M3 represents the specimens with partial replacement of $\mathrm{CA}$ with 30, 40, 50 percentage of RBA. M4, M5, M6 specimens were cast by maintaining at constant percentage of RBA (30\%) and varying the percentage of SF of the order of $0.5,0.75,1$. A addition of $1 \% \mathrm{SF}$ was found to be beneficial in attaining the required strength of concrete specimen. The ideal mix proportion attained was adopted in the fabrication of SCC column of dimension $150 \times 150 \times 1500 \mathrm{~mm}$. After 28 days of curing the columns were subjected to axial loading under the loading frame of capacity $100 \mathrm{~T}$. The deformation corresponding to the load applied, buckling behaviour and development of cracks were observed.

\subsection{Fresh and hardened state properties}

Fresh and hardened state properties of specimens was tested by following the guide lines given in IS standards. Flow ability, passing ability and viscosity values are determined by using slump flow, J-ring, L-box and V-funnel tests respectively and the results are tabulated in table I. The hardened state properties such as compressive, flexural and tensile strength values are determined to investigate the behaviour of each mix prepared for casting column specimens and the values are tabulated in Table II.

Table I Fresh state Properties

\begin{tabular}{|c|c|c|c|c|c|}
\hline \multirow{3}{*}{$\begin{array}{l}\text { Specimen } \\
\text { ID }\end{array}$} & \multicolumn{5}{|c|}{ Fresh state test } \\
\hline & \multicolumn{2}{|c|}{ Slump flow } & \multirow{2}{*}{$\begin{array}{c}\text { J- } \\
\text { ring } \\
(\mathrm{mm})\end{array}$} & \multirow{2}{*}{$\begin{array}{c}\text { L- } \\
\text { Box } \\
(\mathbf{m m})\end{array}$} & \multirow{2}{*}{$\begin{array}{c}\text { V- } \\
\text { Funnel } \\
\text { (Sec) }\end{array}$} \\
\hline & $\begin{array}{c}\mathbf{D} \\
(\mathbf{m m})\end{array}$ & $\begin{array}{c}\mathbf{T}_{500} \\
(\mathbf{S e c})\end{array}$ & & & \\
\hline M0 & 738 & 2.05 & 7.2 & 1.05 & 8.29 \\
\hline M1 & 729 & 2.15 & 7.6 & 0.97 & 8.95 \\
\hline M2 & 726 & 2.96 & 7.8 & 0.93 & 9.25 \\
\hline M3 & 722 & 3.07 & 8.4 & 0.87 & 9.49 \\
\hline M4 & 719 & 3.65 & 8.9 & 0.85 & 10.25 \\
\hline M5 & 715 & 3.87 & 9.3 & 0.83 & 10.87 \\
\hline M6 & 703 & 4.05 & 9.9 & 0.81 & 11.09 \\
\hline
\end{tabular}

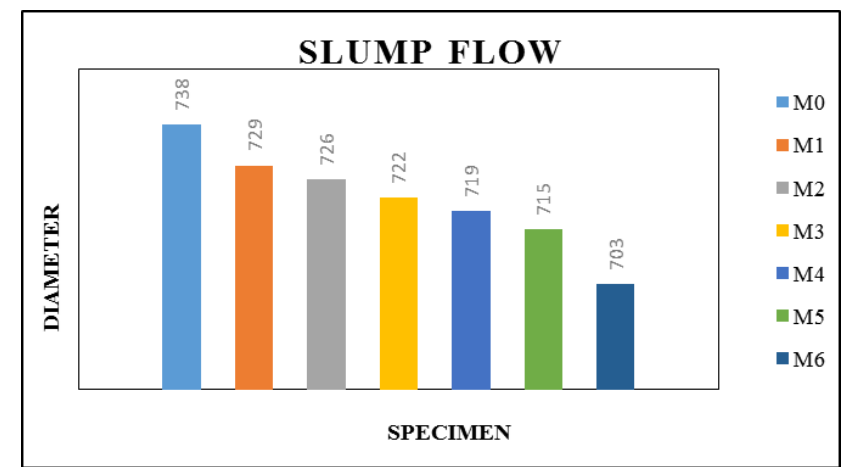

Figure 1 Slump flow value of SCC mix
From the figure 1 , it is evident that the flow ability of SCC mix is higher for control mix and lower with increase in RBA content in SCC mix. This is due to the weakening of binding behaviour between RBA and the binder.

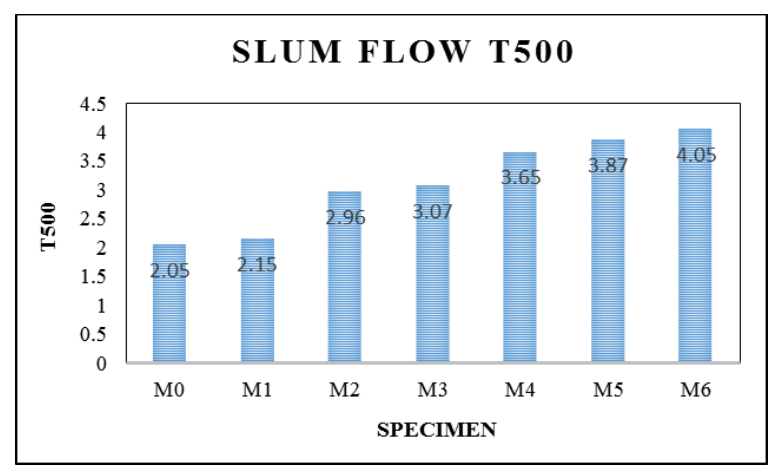

Figure 2 T500 of slump flow time of SCC mix

Flow time values of SCC mix was calculated by using T500 values. The values indicated that the flow times of SCC mix with RBA content increases with increase in RBA amount in SCC. The values are represented using Figure 2

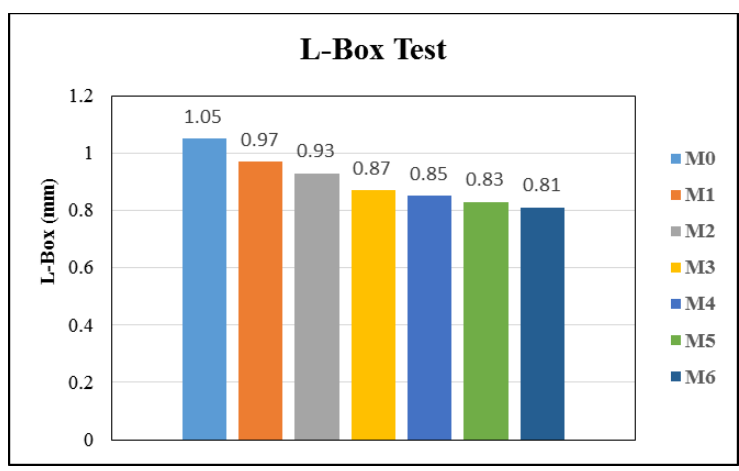

Figure 3 L-Box Test

The filling and the passing ability of SCC mixes are measured by performing L-box test .Figure 3 represents the values of L-Box tests. Filling and passing abilities reduces with increase in RBA content.

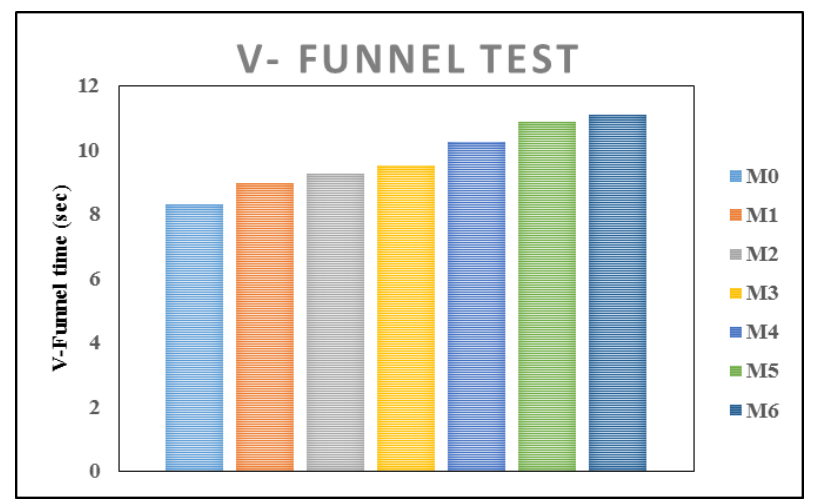

Figure 4 V-Funnel Test

Flow ability of the SCC was also determined by using Vfunnel test and the values are tabulated in table I and represented in figure 4 . Flow ability tests also reduced with increase in RBA content in SCC mix. 


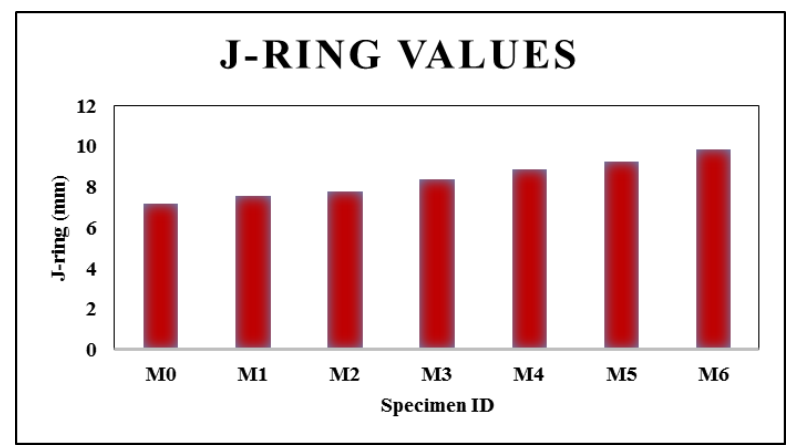

Figure 5 J-Ring Values of SCC mix

J-ring values are tabulated in Table I and the values are represented in figure 5. J-ring values are increased with increase in RBA content.

\subsection{Casting Column Specimens}

The experimental program was carried out in two phases. The first phase involved casting of SCC specimens for validating the performance of SCC produced with RBA and the second phase involved evaluation of the loading and cracking behavior of column. Columns were cast with various amounts of RBA content and fiber content and tested under pure axial loading. The column was cast with the cross-section size of 150 x $150 \mathrm{~mm}$. Longitudinal reinforcement was provided in columns with the bar diameter of $12 \mathrm{~mm}$ and the stirrups spacing fixed at $150 \mathrm{~mm}$ for getting better strength in columns. Specimens were designated as M0 (Normal Self Compacting concrete) was produced with normal concrete constituents. M1 column was cast with $30 \%$ of brick bats. Similarly M2 and M3 were

Table II. Hardened State Properties

\begin{tabular}{|c|c|c|c|c|c|c|c|c|c|}
\hline \multirow[t]{3}{*}{ Specimen ID } & \multicolumn{9}{|c|}{ Hardened state test } \\
\hline & \multicolumn{3}{|c|}{ Compressive strength $\left(\mathrm{N} / \mathrm{mm}^{2}\right)$} & \multicolumn{3}{|c|}{ Flexural strength $\left(\mathrm{N} / \mathrm{mm}^{2}\right)$} & \multicolumn{3}{|c|}{ Split tensile strength $\left(\mathrm{N} / \mathrm{mm}^{2}\right)$} \\
\hline & $7 \mathrm{D}$ & $14 \mathrm{D}$ & $28 \mathrm{D}$ & $7 \mathrm{D}$ & $14 \mathrm{D}$ & $28 \mathrm{D}$ & $7 \mathrm{D}$ & $14 \mathrm{D}$ & $28 \mathrm{D}$ \\
\hline M0 & 18.34 & 24.72 & 37.45 & 2.51 & 3.29 & 3.53 & 1.95 & 2.65 & 2.99 \\
\hline M1 & 17.75 & 21.12 & 34.32 & 2.34 & 2.56 & 3.24 & 1.88 & 2.43 & 2.85 \\
\hline M2 & 14.71 & 18.89 & 28.14 & 2.25 & 2.55 & 3.05 & 1.77 & 2.16 & 2.77 \\
\hline M3 & 11.32 & 15.56 & 25.61 & 2.26 & 2.85 & 2.86 & 1.68 & 2.06 & 2.66 \\
\hline M4 & 17.86 & 22.30 & 35.68 & 2.56 & 2.87 & 3.25 & 1.98 & 2.48 & 2.99 \\
\hline M5 & 18.45 & 23.24 & 36.14 & 2.75 & 2.89 & 3.35 & 1.99 & 2.54 & 3.01 \\
\hline M6 & 18.87 & 25.37 & 37.45 & 2.94 & 2.96 & 3.50 & 2.06 & 2.68 & 3.12 \\
\hline
\end{tabular}

cast with $30 \%$ and $40 \%$ replacement of CA with brickbats. From the above specimens, $30 \%$ of replacement of brickbats provides better compressive strength, so the steel fiber content was varied from 0.5 to $1.0 \%$ and named as M4 for $0.5 \%$ steel fiber content. Similarly, M5 and M6 having $0.75 \%, 1 \%$ of SF content were cast. Finally, these specimens were tested to determine the optimum values of $\mathrm{CA}$ replacement and SF content.

\subsection{Test on Columns}

Cast and cured column specimens were subjected to pure axial loading test in $1000 \mathrm{kN}$ capacity. Universal Testing Machine was used to test the columns with the loading rate of $10 \mathrm{kN}$., and the displacement rate is about $0.004 \mathrm{~mm}$. Four linear voltage displacement transducers were placed at the corners of the columns which is used to measure axial deformations of columns due to the applied load. The reinforcement provided in the columns increased its strength and ductility properties.

\section{5.0 RESULTS AND DISCUSSION}

\subsection{Failure Mode and Crack pattern study}

Test specimens showed similar behaviour and no cracks are available at the initial stages of loading. There is no deflection at the initial stages of loading. As the load was increased, small cracks appeared and propagated slowly. When $85 \%$ of ultimate load was reached, the crack intensely increases and slight voice of failure appeared at the column.
As reaching to the ultimate load the column failed with the loud sound. The failure mode of the M0, M1, M2, M3, M4, M5 and M6 were determined using the load vs. deflection value.

\subsection{Load Carrying Capacity}

The load carrying capacity of the concrete columns fabricated using RBA decreased with increase in RBA content. This is due to the reduction of bonding strength between the Recycled brick aggregates and the binder. Normally increasing steel fibre content in column production increased load carrying capacity of column by 25\%. M6 column specimens exhibited better load carrying capacity which is better than the M3 specimens. This is due to the high proportion values of steel fibres.

\subsection{Load axial deformation behaviour}

Comparison between analytical and experimental load axial behaviours of SCC columns reinforced with steel fibre was carried out in this investigation. Analytical results of axial load curve were perfectly matched with the experimental results until it reaches a maximum value of deformation. This correlation is due to the linearity of the stress-strain behaviour of columns until it reaches the maximum load. The load axial analytical results of the 
descending part curve also exhibited good agreement with the experimental results. The experimental results of axial load show every rise and drop of the response, but in the analytical results, small changes have not been captured properly.

Table IIIColumn test results

\begin{tabular}{|l|l|l|l|l|}
\hline $\begin{array}{l}\text { Specimen } \\
\text { ID }\end{array}$ & $\begin{array}{l}\text { Axial } \\
\text { Load }\end{array}$ & $\begin{array}{l}\text { Axial } \\
\text { Deformation }\end{array}$ & $\begin{array}{l}\text { Cross } \\
\text { section } \\
\text { area }\end{array}$ & $\begin{array}{l}\text { Axial } \\
\text { strain } \\
\mathbf{x 1 0} \\
(\mathbf{m m})\end{array}$ \\
\hline M0 & 565.61 & 7.97 & $150 \times 150$ & 0.5 \\
\hline M1 & 550.29 & 8.27 & $150 \times 150$ & 0.5 \\
\hline M2 & 535.58 & 8.52 & $150 \times 150$ & 0.5 \\
\hline M3 & 513.75 & 8.53 & $150 \times 150$ & 0.5 \\
\hline M4 & 553.26 & 8.35 & $150 \times 150$ & 0.5 \\
\hline M5 & 559.23 & 8.25 & $150 \times 150$ & 0.5 \\
\hline M6 & 560.52 & 8.13 & $150 \times 150$ & 0.5 \\
\hline
\end{tabular}

The test results of column tests are tabulated in Table III. Axial strain values are calculated by using deformation values and the cross sectional areas of the column specimens.

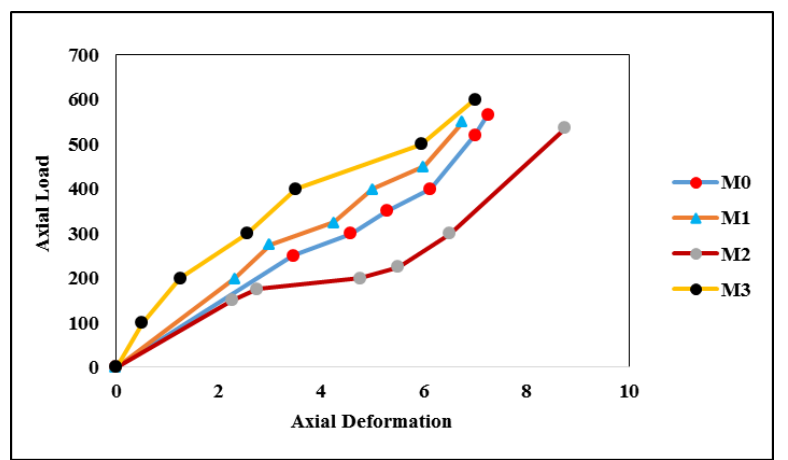

Figure 6 Axial deformation curves of M0, M1, M2, and M3

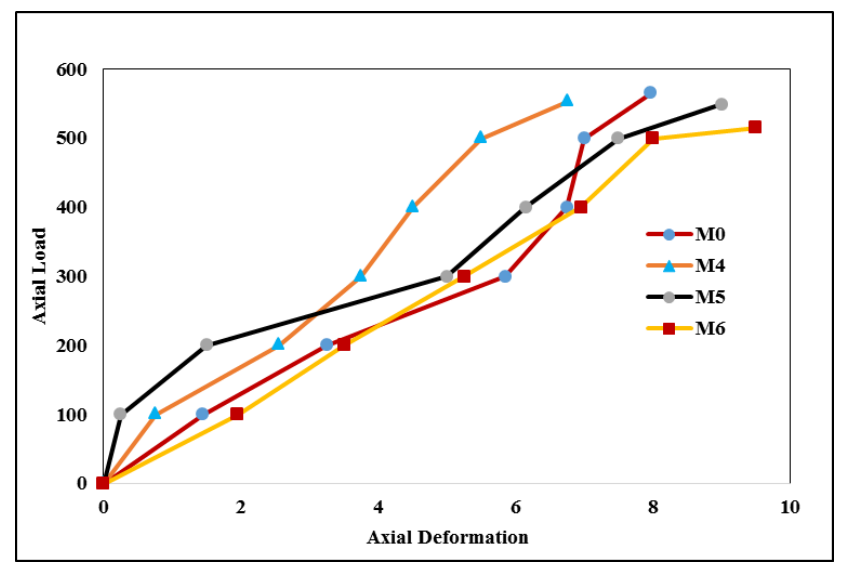

Figure 7 Axial deformation curves of M0, M4, M5, and M6

\subsection{ANSYS RESULTS}

Finite Element Modelling of column specimens was performed by using ANSYS software. These analytical results were satisfactorily agreed with the experimental results. Loads are applied at the column specimens and deformation values are noted. The results are shown in figure 8 to 14

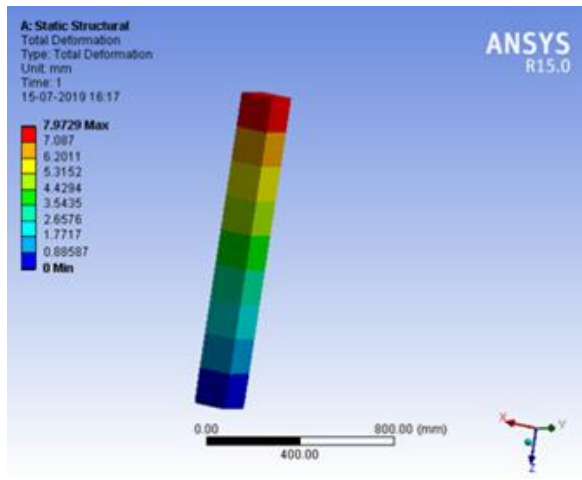

Figure 8 Deflection of M0 Column

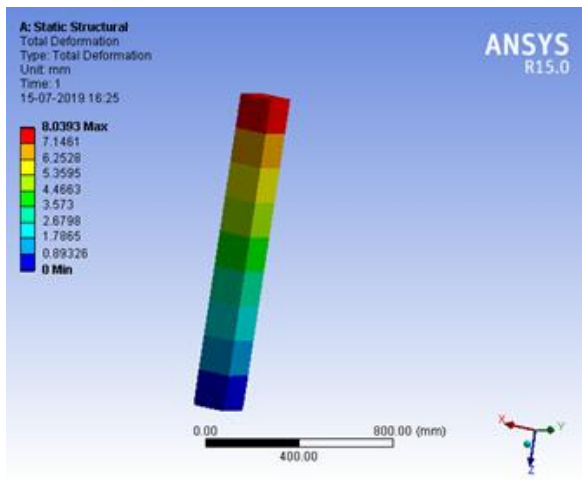

Figure 9 Deflection of M1 Column

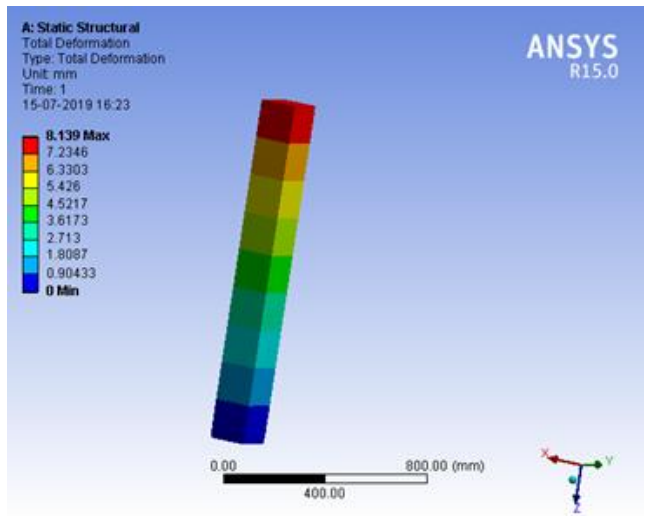

Figure 10 Deflection of M2 Column

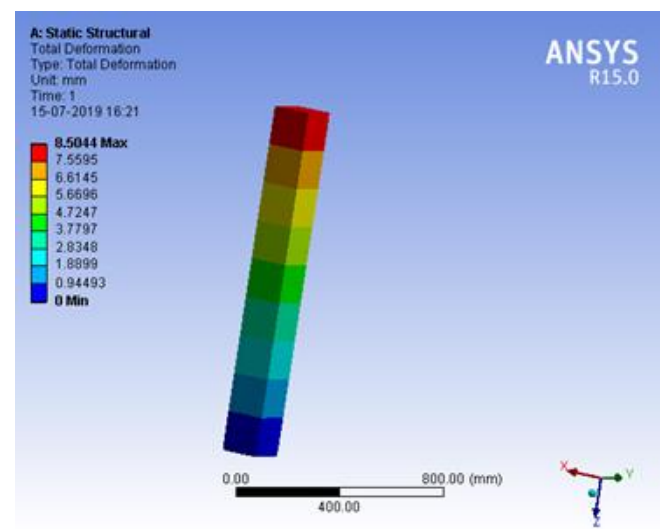

Figure 11 Deflection of M3 Column 


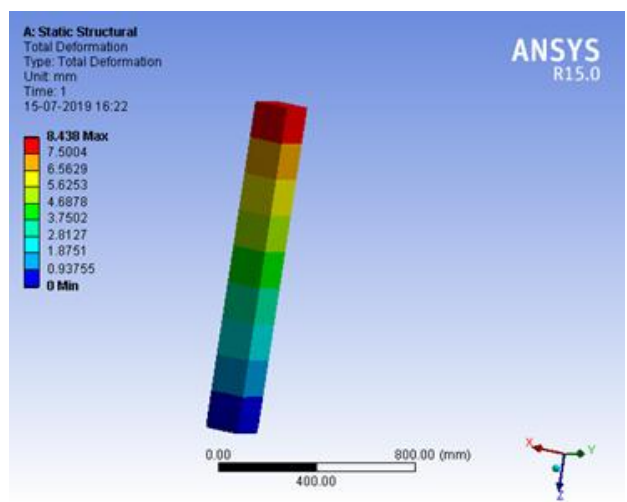

Figure 12 Deflection of M4 Column

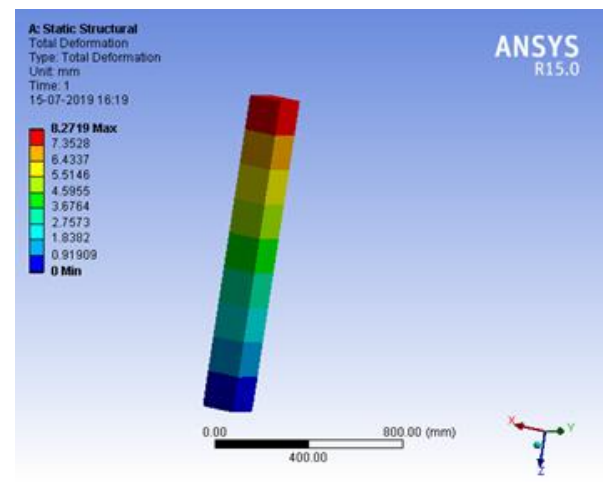

Figure 13 Deflection of M5 Column

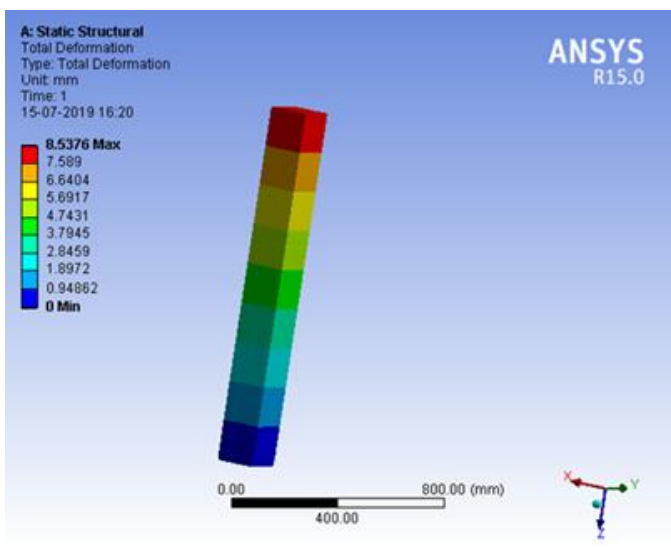

Figure 14 Deflection of M6 Column

\section{CONCLUSIONS}

Based on the test results the following conclusions are made and it takes this research to the next level. Column specimens using RBA paves a way to use recycled aggregates which reduces the exploitation of natural resources. The load carrying capacity of the column specimens reduced with increase in RBA content in SCC mix. Steel fibre reinforcement in columns plays an important role in improving load carrying capacity it enhanced the load carrying capacity by $20 \%$. Increasing the volumetric ratio of steel fibre content in column specimens further increase the strength properties of column specimens. Compressive strength values of column specimens decreased with increase in slenderness ratio.

\section{REFERENCES}

1. Wenzhong Zhu, John C. Gibbs, Peter J.M. Bartos, Uniformity of in situ properties of self-compacting concrete in full-scale structural elements, Cement and Concrete Composites, Volume 23, Issue 1, 2001, Pages 57-64, ISSN 0958-9465, https://doi.org/10.1016/S0958-

9465(00)00053-6.

2. Zhi-wu Yu, Fa-xing Ding, C.S. Cai, Experimental behavior of circular concrete-filled steel tube stub columns, Journal of Constructional Steel Research, Volume 63, Issue 2, 2007, Pages 165-174, ISSN 0143-974X, https://doi.org/10.1016/j.jcsr.2006.03.009.

3. Shen, W., Liu, Y., Yan, B., Wang, J., He, P., Zhou, C., Huo, X., Zheng, W., Xu, G., 612 Ding, Q., 2017. Cement industry of China: Driving force, environment impact and 613 sustainable development. Rene. Sust. Ener. Revi. 75, 618-628

4. Ge, Z., Wang, Y., Sun, R., Wu, X., Guan, Y., 2015. Influence of ground waste clay brick on properties of fresh and hardened concrete. Constr. Build. Mater. 98, 128- 555136

5. Debeib, F., Kenai, S., 2008. The use of coarse and fine crushed bricks as aggregate in Concrete. Constr. Build. Mater. 22 (5), 886-893

6. Padmini, A. K., Ramamurthy, K., Mathews, M.S., 2002. Relative moisture movement through recycled aggregate concrete. Mag. Concr. Res. 54(5), 377-384.

7. Vieira, T., Alves, A., Brito, J.D., Correia, J.R., Silva, R.V., 2016. Durability-related performance of concrete containing fine recycled aggregates from crushed bricks and sanitary ware. Mater. Des. 90, 767-776.

8. Gomes, M., Brito, J.D., 2009. Structural concrete with incorporation of coarse recycled concrete and ceramic aggregates: durability performance. Mater. Struct. 42(5), 558 663-675.

9. Hassan M, Ahmed E, Benmokrane B. Punching-shear strength of normal and highstrength two-way concrete slabs reinforced with GFRP bars. J Compos Construction 2013;17(6):04013003

10. Kristiawan SA, Nugroho AP. Creep behaviour of selfcompacting concrete incorporating high volume fly ash and its effect on the long-term deflection of reinforced concrete beam. Procedia Eng 2017;171:715-24. 